\title{
Desigualdades de clase y género en los horizontes de expectativas para los hijos e hijas de familias de clase media del área metropolitana de Buenos Aires*
}

\author{
Mercedes Krause*
}

\section{Resumen}

El objetivo del artículo es discutir en qué medida la clase social y el género influyen en los horizontes de expectativas de familias de clase media metropolitana, monoparentales y biparentales, con hijos menores. El trabajo se enmarca dentro de un estudio que vincula el análisis del sentido común con las prácticas de clase alrededor del cuidado de la salud y la educación, incorporando la vertiente de análisis fenomenológica al estudio weberiano de las clases sociales. Analizamos veinte entrevistas biográficas semiestructuradas realizadas en dos etapas de trabajo de campo durante 2009 y 2013.

Articulando la perspectiva de la desigualdad de clase con la de género identificamos las tipificaciones y normas esperadas en la generación de los sucesores. En cuanto a la clase social, vemos que los padres y madres de clase media entrevistados van tomando decisiones previendo y anticipando posibles destinos que escapen a su horizonte de expectativas, ya sean relativos a sus actividades laborales, sus lugares de pertenencia o sus actividades de esparcimiento. En cuanto al

\footnotetext{
* Artículo recibido el 23 de junio de 2014. Aceptado el 15 de octubre de 2014.

${ }^{*}$ Mercedes Krause pertenece al IIGG-UBA/CONICET.

Correo electrónico: merkrause@gmail.com
} 
género, constatamos que desde muy temprana edad, y aun antes de que surjan diferencias en el rendimiento académico y aspiraciones futuras, circulan en la familia conceptos de sí mismos que asocian a los varones con la matemática e ingeniería y a las mujeres con el cuidado y la docencia.

\section{Palabras clave}

Clases sociales - Género - Reproducción social.

\section{Abstract}

The aim of the paper is to discuss the extent to which social class and gender influence the horizons of expectations towards children in metropolitan middle-class families with young children. The work is part of a study linking the common sense analysis with everyday practices around health care and education, incorporating the phenomenological analysis in the Weberian study of social classes. We analyze twenty semi-structured biographical interviews carried out in two stages of fieldwork in 2009 and 2013.

Articulating the social classes and gender inequalities we identify the norms and typifications expected in the generation of successors. In terms of social class, we see that middle class families making decisions foreseeing and anticipating risks or locations that are outside their middle class expectations horizons; these could be work activities, places of belonging or leisure activities. Regarding gender, we suggest that from an early age, and even before differences in academic performance and future aspirations arise, selfconcepts that associate men with mathematics and engineering and women with care and teaching are circulating in the family.

\section{Keywords}

Social classes - Gender - Social reproduction.

\section{Introducción}

El presente artículo constituye una aproximación al análisis de las expectativas que los padres y madres de clase media del Área Metropolitana de Buenos Aires (AMBA) tienen para la generación que integran sus hijos e hijas. Específicamente, discutimos las 
representaciones que veinte familias entrevistadas han constituido como trayectorias de clase media y qué conceptos tienen acerca de los estereotipos tradicionales de género. Esta temática adquiere especial interés en el marco de un estudio cuya finalidad es comprender cuáles son los mecanismos de construcción del conocimiento de la clase media metropolitana y de su autotipificación y de qué modo los padres y madres definen su situación en el mundo y actúan en él respecto de la salud y educación familiares -a través de un análisis cualitativo que incorpora la vertiente de análisis fenomenológica al estudio weberiano de las clases sociales. ${ }^{1}$ Nuestra inquietud por el análisis del sentido común vinculado al análisis de clase nos ha llevado a interesarnos por los debates sobre la reproducción de las clases sociales en el entorno familiar, dentro de los estudios de estratificación social centrados en los enfoques microsociales. Por lo tanto, orientamos el estudio hacia las prácticas cotidianas de las familias de clase media en dos aspectos fundamentales para la reproducción social como son la salud y la educación.

Elegimos la perspectiva fenomenológica porque permite abordar el significado, la estructura y la esencia de la experiencia vivida por un grupo de personas sobre un fenómeno determinado -en este caso, la reproducción de las clases sociales. Es un enfoque que incorpora lo objetivo en su análisis de las experiencias comunes a los miembros de una sociedad o grupo determinado, que se centra en la esencia de la experiencia compartida (Patton, 2002). Retomando a Husserl, Schütz se propone buscar "la estructura invariable, única, a priori de la mente, en particular de una sociedad compuesta por mentes vivientes" (Schütz, 1993: 74). En este sentido, la fenomenología social permite la descripción de las estructuras y actividades fundamentales de la conciencia individual que deben ser tomadas en consideración para describir la acción social (Dreher, 2012). Ello, siempre teniendo presente como trasfondo una apreciación de la estructura social dentro de la cual se produce la internalización de la misma (Berger y Luckmann, 2008).

Este trabajo supuso el esfuerzo por tratar de acercarnos al uso de las herramientas fenomenológicas para el análisis empírico de la problemática de las clases sociales en el marco de una teoría de la acción social y las relaciones sociales. En este nexo entre la posición de Schütz y el problema de las clases sociales no podemos más que tematizar las nociones schutzianas y de los seguidores de la tradición fenomenológica que puedan aportar al análisis de la estructura de clases. Se trata de un razonamiento inspirado en Schütz, y no de afirmaciones suyas. Para ello recuperamos los aportes de Schütz a la teoría de la experiencia subjetiva del mundo social y los trasponemos hacia el terreno de la cultura de clase. Proponemos pensar la situación biográfica como ámbito de experiencias de vida que impone ciertas relevancias y posibilita otras -

\footnotetext{
${ }^{1}$ Este artículo forma parte de la tesis de maestría de la autora (Krause, 2014). Una versión preliminar de este trabajo fue presentada en 2013 en las VII Jornadas de Jóvenes Investigadores del Instituto de Investigaciones Gino Germani en Buenos Aires.
} 
algunas no conscientes. Como hemos argumentado en otro trabajo, en la definición del mundo de la vida está implícita la estructura social que condiciona la situación biográficamente determinada del individuo y que define contextos típicos de experiencias y actos y posibilidades de interacción social. También abordamos previamente la importancia de la familia en la transmisión del acervo social de conocimiento al individuo como nuevo integrante de la clase social (Krause, 2011). Aunque Schütz no lo aborda como cultura de clase, este problema coincide con la función decisiva de la familia en la socialización y educación de la persona. Por lo tanto, la biografía está fuertemente condicionada por la familia de origen y por la cultura filtrada a través de la estructura social que el niño adquiere e internaliza a través de las Ilamadas Relaciones Nosotros. Las Relaciones Nosotros son situaciones cara a cara que trascienden la existencia de cualquiera de los asociados y que, por lo tanto, solo pueden ser apresentadas por medio de la simbolización (Schütz, 2003). ${ }^{2}$ Se trasciende entonces el ámbito finito de sentido del ejecutar cotidiano a través de la cultura que se comparte con los contemporáneos [Nebenmenschen], pero que se extiende también hacia los predecesores [Vorwelt] y los sucesores [Folgewelt] a través de la memoria y de las expectativas.

En este trabajo analizamos entrevistas biográficas semiestructuradas realizadas en dos etapas durante el trabajo de campo en el 2009 y el 2013, con padres y madres de veinte familias de diferentes posiciones de clase media seleccionadas a partir de un estudio cuantitativo previo sobre los patrones de movilidad e inmovilidad social intergeneracional en el AMBA (Dalle, 2009). ${ }^{3}$ Para explorar sus expectativas a futuro como una dimensión de su conocimiento de sentido común, preguntamos durante las entrevistas, por un lado, cuáles son sus propias expectativas como padres y madres para el futuro de sus hijos e hijas $y$, por otro, cuáles creen que son las metas de sus hijos e hijas para el futuro. Aquí analizamos ambos aspectos del relato como un todo, considerando que las visiones de las madres y los padres hacen referencia a su sentido común y la visión que ellos tienen sobre el futuro y metas de sus hijos e hijas.

\section{Horizontes de expectativas para los hijos e hijas}

Al tematizar sus expectativas, encontramos un núcleo temático central e imágenes compartidas por las familias a pesar de la variedad en la composición de los hogares y las edades de los hijos e hijas. Este núcleo de ideas compartidas tiene como eje

\footnotetext{
${ }^{2}$ Schütz llama apresentación a la forma de acoplamiento o apareamiento característica de cualquier experiencia en la actitud natural por medio de la cual un objeto, hecho o suceso es percibido como representación de otro que no está inmediatamente dado al sujeto (Schutz, 2003; Knoblauch, 1999).

${ }^{3}$ Se trata de un estudio que forma parte del proyecto UBACyT S051, 2008-2010, El análisis de clase: formación histórica y enfoques microsociales, Instituto de Investigaciones Gino Germani, UBA, Directora: Dra. Ruth Sautu. Los datos sobre las familias fueron proporcionados por las encuestas sobre Estratificación y movilidad social en la Argentina aplicadas en 2004, 2005 y 2007 por el Centro de Estudios de Opinión Pública (CEDOP) del Instituto de Investigaciones Gino Germani, UBA, Director: Dr. Jorge Raúl Jorrat. Las tres muestras fueron nacionales, estratificadas multietápicas, con selección aleatoria en todas las etapas del muestreo.
} 
articulador un contexto social que perciben como desigual y excluyente. En ese contexto destacan la capacidad de agencia de sus familias en el aprovechamiento de oportunidades y ventajas estructurales para la construcción de su trayectoria de clase media y perpetúan hacia sus hijos e hijas la imagen que tienen de sí como familia, con sus valores y costumbres, sus trayectorias educativas y ocupacionales. Asimismo, sostienen su intención de proteger o sobreproteger a sus hijos e hijas respecto de "riesgos" sociales o destinos que están por fuera de sus horizontes de expectativas de clase media: ya sean actividades laborales, lugares de pertenencia o actividades de esparcimiento.

Podríamos decir que sus expectativas tienden a reproducir las recetas sociales conocidas. Sin embargo, las expectativas de los padres para los hijos e hijas también están permeadas por cierto nivel de incertidumbre. Los padres notan una singularización creciente de los cursos de vida posibles:

O sea que [mis hijas] la van a tener que luchar desde todo, desde económico hasta lo ecológico, hasta una serie de cosas que yo creo que hay un futuro [silencio] diferente para ellos. Desde lo sexual, también, con normas totalmente diferentes, con libertades diferentes. O sea que es difícil proyectarlo me parece ¿no? Con todas las cosas nuevas que hay, yo a los 45 años veo, no sé, un montón de cosas que no sé por ahí si le preguntabas a mi mamá iba a decir 'sí, mi hija se va a casar' o no y 'va a tener hijos' y punto. Hoy no sé, no sé para dónde irá, qué definición sexual tendrá, si podrá formar una familia, si decidirá irse, no sé. Como que hay mucha libertad para que hoy puedan elegir muchas cosas que antes no. (Madre de la familia 12).

La singularización de las trayectorias biográficas permite a esta madre incorporar "nuevos referentes" en cuanto a normas y modelos de familia, como otras libertades sexuales y la posibilidad de migrar. En esta familia lo que se resalta es una incertidumbre de tipo positiva, en el sentido de posibilidades abiertas que hoy -y "antes no"- sus hijas pueden elegir "para fabricarse como sujeto" (Martuccelli, 2010: 14):

No me parece que esté buena la vida del 'estudio, me recibo, voy a trabajar y me quedo en ese trabajo' y ¿viste? Y nada. No, me parece que hay que volar, hay que buscar otras oportunidades, otros lugares. Creo que esa mente hoy la tienen los chicos más, más amplia. Si bien tienen menos responsabilidad me parece, por eso, esa menos responsabilidad va a hacer que también otras posibilidades de elegir cosas diferentes. (Madre de la familia 12).

Como resulta evidente, este contexto de mayor autonomía en cuanto a deberes fijados sobre los cursos de vida es percibido como positivo porque estas familias 
cuentan con recursos prácticos y ventajas de clase. En la medida en que el estudio y el trabajo se suponen a su alcance, el riesgo refuerza constantemente "los valores de autodesarrollo" de la clase media (Ball, 2003: 149). Esta singularización creciente de los cursos de vida posibles, además, se relaciona con sus memorias y trayectorias familiares. Así como la autotipificación de las trayectorias familiares, las expectativas para los sucesores también se ven atravesadas por vivencias pasadas y legados culturales. La madre de la familia 12 es proveedora de un hogar monoparental. Con dos hijas mujeres, se divorció a los 35 años y actualmente no cuenta con redes de apoyo informal más allá de la ayuda de su madre en el mantenimiento del hogar. Resulta lógico, entonces, que considere positivo un clima de mayor libertad respecto de configuraciones familiares y cursos de vida posibles y aprobadas socioculturalmente. No obstante, otras familias interpretan que el futuro está marcado por cierta incertidumbre negativa, en el sentido de imprevisibilidad e inseguridad respecto de su posición social y condiciones de vida. En este sentido, la madre de la familia 14 problematiza la continuidad de estándares de vida de la clase media. Al compararse con sus padres juega con una identidad familiar de clase media que, según su percepción, no encuentra un correlato en las condiciones de su propia vida:

A mí [mis padres] me dijeron, me informaron, que yo era clase media con aspiraciones... hoy quedaron las aspiraciones, como a nivel país. (...) Respecto de ellos [mis padres] tengo dos cuestiones: una, mi mamá, digamos, no siempre [pero] tenía una persona cada tanto que la ayudaba, por lo menos semanalmente, en las tareas domésticas. Y luego, fundamentalmente, tenían obra social... y otra cosa que perdí, que en cualquier momento estoy por recuperar [risas] son las vacaciones porque realmente, o sea, este año logré dejarme una semana para irme a San Clemente del Tuyú y... [risas] patético. (...) Otra cosa también que en cualquier momento recupero pero... jel auto! El auto. No yo, porque no manejo, [pero] mi marido... el auto lo extraña más él que yo (...) Respecto de mis padres, mis padres tenían auto, mis padres tenían la obra social, aunque sea cada dos o tres años se iban de vacaciones, o sea, eso sí... o sea, evidentemente no es un tema mío, hay otras personas que están en la misma situación. Lo que a mí sí un poco me molesta, me hace ruido, es que no es que uno se priva de ciertas cosas en pos de algo mejor en otro momento. No, en pos de algo mejor sería que yo, individualmente, me supere en algunas cuestiones, porque a nivel grupal yo no veo que haya hacia dónde ir. (Madre de la familia 14).

Así, la madre de la familia 14 identifica espontáneamente ciertos indicadores y consumos que le sirven para comparar su situación con la de sus padres durante su juventud, como son el servicio doméstico, la cobertura de salud, las vacaciones y el auto. Hacia el final hace referencia a la distinción conceptual entre movilidad social estructural -"algo mejor"- y movilidad social individual o por reemplazo -"que yo, 
individualmente, me supere". Contrapone implícitamente su situación actual con una situación que se dio en la Argentina en la época de la inmigración masiva, cuando las aspiraciones de movilidad social estaban inspiradas por una ampliación estructural de las posiciones de clase media a ocupar (Germani, 1963). En la actualidad, en cambio, la madre percibe una generación perdida: "no hay ahora supuestamente, desaparecidos físicos, pero bueno... yo te digo, mucha gente que podía crecer económica, socialmente, y blah se está también borrando. Entonces, yo no sé, a ver, qué es mejor... o sea, matarlo de un tiro o dejar que se desangre" (madre de la familia 14). Con una comparación tan fuerte como esta con los desaparecidos hace referencia al fenómeno del desclasamiento y las emociones que este implica. Teniendo en cuenta la hostilidad percibida en el contexto actual que marcábamos, supone que no va a mejorar su posición ni poder estructuralmente, y que solo le cabe la posibilidad de mejorar su situación individual mientras que otro cae, y "desaparece". A través de sus vivencias y de su memoria, esta madre entiende la movilidad social de recambio como la única posibilidad de "superación" familiar. ${ }^{4}$

En la misma línea de pensamiento, otros padres notan una devaluación de las credenciales educativas de nivel medio en relación a la época en que ellos se insertaron en el mercado laboral: "con el secundario no te alcanza. Yo, como le digo a mi hija: 'vos con el título secundario, ¿qué vas a ser?, solamente cajera en el supermercado' (...). Cuando yo era chica, por ejemplo, me acuerdo que terminabas el secundario y vos podías emplearte en lugares donde necesitaban una empleada administrativa. $Y$ ahora no sé, no creo que haya" (madre de la familia 16). A su vez, notan la devaluación de las credenciales educativas de nivel superior y la valorización de los títulos técnicos por sobre los profesionales: "te soy sincera, vale más en este momento un 'técnico en...' que un título médica, ingeniero, que antes era lo básico de todo el mundo quería 'ay, quiero ser médico' 'quiero ser ingeniero o abogado'. Hoy en día para uno vivir bien no importa ser doctor en ese sentido" (madre de la familia 15). Algunos de los padres entrevistados perciben una fuerte concentración de sectores medios profesionales que constituye una barrera de acceso a ocupaciones intelectuales. ${ }^{5}$ En contraste con otras épocas, el hecho de vivir en el AMBA ya no es percibido como una ventaja: "uno ve que a pesar de tener un título en la mano les cuesta un montón. Porque la centralización de profesionales queda toda en Buenos Aires. Es como que... es más difícil" (madre de la familia 15). Estas familias que interpretan que el futuro está marcado por cierta incertidumbre negativa, encuentran que las oportunidades que el país y el AMBA les pueden brindar para el futuro son deficientes e inciertas. Por lo tanto, consideran las

\footnotetext{
${ }^{4}$ Así, en su ejecutar cotidiano da cuenta en cierta forma de los estudios de estratificación social de Jorrat (2005) que sugieren que la desigualdad social y exclusión conviven con altos índices de movilidad ocupacional (de clase) ascendente en la sociedad argentina actual.

${ }^{5}$ Esto coincide con los resultados de un estudio cuantitativo que marca que la primacía de los ocupados en puestos en la rama de los Servicios $(60,5 \%)$ y el Comercio $(24,1 \%)$ como una de las particularidades de la estructura socioeconómica de CABA (Fernández Melián, Rodríguez de la Fuente y Clemenceau, 2013).
} 
migraciones al exterior como una posibilidad de ascenso social y mejoramiento de sus condiciones de vida: "vivimos siempre en el dilema de qué tenemos que hacer, cómo tenemos que educar a nuestros hijos, ¿no? ¿Para trabajar acá o para trabajar afuera?" (Padre de la familia 13)

Asimismo, la adquisición de credenciales educativas ya no garantiza el acceso a una ocupación de clase media. Las capacidades requeridas por el mercado laboral ya no son las mismas que antes y se vuelven más subjetivas:

En el nuevo paradigma no interesa, igual, cuántos estudios tenés, sino que si tenés la astucia, la ética y los valores como para llevar eso adelante. Porque hoy por hoy no es como cuando nosotros éramos más chicos, el verso del momento era 'no, si estudiás para abogado, para contador...'. Todavía hay gente que cree eso, que si tenés una carrera formal de... que te habilita como contador, como escribano, no vas a tener problemas, entre comillas, en lo económico y demás y eso no es así. Hoy por hoy, podés... Un profesor de gimnasia lo valorás, lo sabés llevar adelante y te puede ir económicamente mejor que quizá un señor que estudia abogacía. Eso ya, hoy por hoy, no. O sea, la época de 'mi hijo, el doctor' ya fue, o sea [risas] quedó dirimida (...) creo que lo que más vamos a precisar es creatividad e innovación y aplicar eso en algo concreto. (Madre de la familia 14).

Aun así emerge con fuerza en los relatos analizados el valor atribuido a la educación como prioridad de la familia. Su preocupación por la educación de sus hijos no refiere solamente a "la educación para tener trabajo" (madre de la familia 8) sino también a la educación como "una buena formación" (madre de la familia 10). Con los cambios en el mercado laboral, se demandan más credenciales educativas formales y, además, otras cualidades y competencias como la "creatividad e innovación" (madre de la familia 14), flexibilidad, autonomía y control (Boltanski y Chiapello, 2005). Estas últimas son cultivadas en los hogares, en cuanto la educación formal se mantiene como un indicador de que los hijos van por buen camino, que están bien orientados dentro del contexto social de incertidumbre:

-Los dos [mis hijos] están bien encaminados, por lo menos a la edad que tienen.

-¿Qué significa 'bien encaminados'?

-Que la perspectiva que tienen es buena. O sea, mi hija estudia en la Universidad de Buenos Aires también, y ya está por recibirse en Ciencias de la Informática y Profesora de Informática en la Universidad de Buenos Aires. Y mi hijo está terminando el secundario en la escuela técnica. (Padre de la familia 17).

De hecho, al responder sobre las expectativas a futuro para sus hijos, los padres comienzan por desear que logren hacer lo que quieran y ser felices, pero inmediatamente después hablan de su educación: 
-¿Y qué expectativas tenés para su futuro?

-Eh... como madre... bien. Que hagan lo que desean y que lo puedan cumplir. Eh... mi hija mayor está estudiando en la universidad, traductorado público eh... traductorado, no público, y mi hijo todavía está en el secundario. Pero bueno que... que se dediquen a lo que desean realmente y que lo puedan cumplir y sean felices haciendo eso. (Madre de la familia 14).

De ambos relatos se desprende que la educación sigue siendo lo certero, un capital cultural heredado que puede, en un futuro, contribuir al progreso de sus hijos, su "salvaguarda" (padre de la familia 2), el "arma en las manos" (madre de la familia 8) para defenderse en un futuro que se percibe como cada día más incierto y hostil. Aunque "la vida decide muchas cosas por uno" (padre de la familia 5), se acentúa el valor de la educación como el único legado que sobrevive a los vaivenes de la historia, como un valor relativo a la cultura de clase y a la propia identidad familiar:

Más allá de que hoy por ahí el estudio no te pueda dar un bienestar económico, o es todo relativo, qué sé yo, es lo que yo les puedo dejar. $Y$ después, no sé, tenemos una casa, un auto. Normal. Más que eso... o sea, me parece que lo mejor que uno le puede dejar a los hijos es el estudio. (Padre de la familia 19).

El logro de metas a nivel educativo se concibe como una herencia propia de una clase media sin grandes fortunas: "nosotros no somos gente de fortuna, entonces la idea era dejarles una buena educación a mis hijos. La opción era esa" (madre de la familia 1). Como afirma Wortman (2003), en estas familias de clase media "se revaloriza la educación no ya como una estrategia de movilidad social sino de permanencia en un lugar adquirido" (p. 40).

A pesar de que la expectativa de que sus hijos hagan "lo que quieran hacer para ser felices" (madre de la familia 7) fue muy repetida a lo largo de las entrevistas, el rango de posibilidades para "hacer" (y ser) viene ya preconceptualizado, tipificado y acotado por el entorno familiar de pertenencia. Aunque los padres postulen la educación superior como una elección personal de sus hijos, y también lo sientan así respecto de sus decisiones educativas durante la juventud, la presión familiar es clara en cuanto al estándar a lograr y las instituciones que lo permiten. La madre de la familia 7 lo expresa de una manera que hace visible el doble sentido entre transmisión e imposición de relevancias. Abogada, al igual que su esposo e hija, recuerda:

-¿Cómo eligieron la carrera?

-Sí, eligieron ellas. (...) Y hacerla en la UBA también. Sí, sí, sí, sí. - ¿Ustedes no les aconsejaban? 
-No, nosotros lo que le dijimos, que nosotros la habíamos hecho en la UBA y que para nosotros la UBA era la mejor. Pero que ellas decidieran. (...) Pero bueno, decidieron por la UBA. (Madre de la familia 7).

\section{Los proyectos de reproducción intergeneracional en la clase media}

Respecto de lo que estamos tratando, Schütz y Luckmann (2001) plantean que el mundo de la vida es un universo de significación que está estructurado en zonas según diversos grados de claridad, nitidez y precisión, y que "la opacidad del mundo de la vida y la índole limitada del acervo de conocimiento se presentan con sumo vigor cuando hay que predecir el futuro, cuando se proyectan actos, se pondera su factibilidad y se calculan sus consecuencias" (p. 170). Como vemos en el siguiente relato, la proyección se encuentra directamente condicionada por el acervo de conocimiento de la clase o grupo social de pertenencia, y ello vale tanto para los planes de vida cotidianos como para los cursos de vida a largo plazo:

Yo quiero que ellos hagan algo que les guste. O sea que si ellos piensan que siendo comerciante van a ser felices y les va a gustar, adelante. Yo aspiro a que ellos sean profesionales. Me gustaría que sea una carrera universitaria. Yo creo que cuantas más herramientas tenga en la mano para desenvolverse en el mundo laboral, mejor. Y la universidad es una buena herramienta. Entonces si ellos después de ser, qué se yo, te digo cualquier cosa, arquitecto, abogado, esteh, no sé, enólogo, ecólogo, qué se yo, lo que fuere, si después quiere ser, trabajar de taxista, bueno, es un tema de ellos. Pero que tenga la posibilidad de ir a la facultad y conocer lo que es el ambiente universitario, desenvolverse. (...) Yo creo que ellos pueden, están en condiciones de hacer una carrera universitaria. Yo voy a hacer, de mi parte, lo que sea. No los voy a obligar, pero me parece que habiendo el papá y la mamá egresado de la universidad, me parece que lo menos que pueden hacer ellos, aunque sea, [es] el esfuerzo de empezar. Buscar algo que les guste y hacerlo. (...) Yo nunca me planteé '¿voy a estudiar?'. [Si]No... '¿Qué voy a estudiar?' (Madre de la familia 1).

Estos padres proyectan ciertas trayectorias mientras que evitan otras, anhelan que sus hijos sean de determinada manera y no de otra, y al comunicarlo en el hogar transmiten a sus hijos cuál es su percepción de las biografías típicas de clase media. De esta forma, integran a sus hijos en un futuro "imaginario" pero "posible y realizable" que les permitirá gestionar sus aspiraciones y ambiciones, y planificar sus pasos en vinculación a su Aquí y Ahora (Ball, 2003: 108-109). "Imaginar produce experiencia", argumenta Tevik (2006: 223). Bourdieu (1998: 482-483) se refiere a este fenómeno como un "dominio práctico del enclasamiento" que "permite actuar como si se conociera la estructura del mundo social y el lugar ocupado en esa estructura, y, al mismo tiempo, las distancias a guardar o a mantener". Entonces, a partir de las 
expectativas que tienen para sus hijos $-\mathrm{y}$ a pesar de que en algunos casos se narren como expectativas de sus hijos en lugar de propias- podemos imaginar lo que estas familias se representan como trayectorias de clase media. En el siguiente cuadro presentamos, del lado izquierdo, aquello que estos padres consideran "riesgos" en relación al futuro de sus hijos; en la parte central, la proyección vinculada a la autotipificación de sí y su situación biográfica (de clase); y, del lado derecho, aquello anhelado como ascenso social.

\section{Cuadro 1: Horizontes de expectativas para los hijos e hijas de clase media del}

\section{AMBA}

\begin{tabular}{|c|c|c|}
\hline "Riesgos" de fracaso & $\begin{array}{l}\text { Proyectos de reproducción en } \\
\text { la clase media }\end{array}$ & $\begin{array}{l}\text { Expectativas de } \\
\text { ascenso social }\end{array}$ \\
\hline $\begin{array}{l}\text { "perdió medio año porque le } \\
\text { quedó una materia" (padre de la } \\
\text { familia 2) }\end{array}$ & & \\
\hline $\begin{array}{l}\text { "no se va a quedar sin nada. } \\
\text { Seguro se toma un año sabático y } \\
\text { después arranca" (madre de la } \\
\text { familia 8) }\end{array}$ & $\begin{array}{l}\text { "que tenga herramientas para } \\
\text { desenvolverse en la vida" } \\
\text { (padre de la familia 5) }\end{array}$ & \\
\hline $\begin{array}{l}\text { "me duele muchísimo que no } \\
\text { siga estudiando" } \\
\text { (madre de la familia 16) }\end{array}$ & $\begin{array}{l}\text { "tiene la personalidad para ser } \\
\text { un estudiante universitario" } \\
\text { (madre de la familia 3) }\end{array}$ & $\begin{array}{l}\text { "por ahí te pueden ayudar a } \\
\text { vincularte" (padre de la familia 2) }\end{array}$ \\
\hline $\begin{array}{l}\text { "cuando mi hija dejó la } \\
\text { universidad me costó" (madre de } \\
\text { la familia 8) }\end{array}$ & $\begin{array}{l}\text { "tiene dotes que tiene que } \\
\text { aprovecharlos" } \\
\text { (padre de la familia 5) }\end{array}$ & $\begin{array}{l}\text { "te recibirás a los } 23 \text {, sos muy } \\
\text { joven y después si querés estudiá } \\
\text { otra cosa" (padre de la familia 2) }\end{array}$ \\
\hline $\begin{array}{l}\text { "ser una bohemia toda la vida" } \\
\text { (madre de la familia 8) }\end{array}$ & $\begin{array}{l}\text { "que sean profesionales" } \\
\text { (madre de la familia 1) }\end{array}$ & $\begin{array}{l}\text { "cuanto más nivel de } \\
\text { educación alcances, mejor" } \\
\text { (madre de la familia 1) }\end{array}$ \\
\hline $\begin{array}{l}\text { "ser bruto" (madre de la } \\
\text { familia 15) }\end{array}$ & $\begin{array}{l}\text { "tienen una carrera, está todo } \\
\text { bien" (padre de la familia 17) }\end{array}$ & $\begin{array}{l}\text { "hacer una maestría" } \\
\text { (madre de la familia 8) }\end{array}$ \\
\hline $\begin{array}{l}\text { "no todos tienen la suerte de } \\
\text { vivir de lo que eligen" } \\
\text { (madre de la familia 20) }\end{array}$ & $\begin{array}{l}\text { "tener más posibilidades a } \\
\text { través del estudio" (madre de la } \\
\text { familia 12) }\end{array}$ & $\begin{array}{l}\text { "poder viajar" } \\
\text { (madre de la familia 12) }\end{array}$ \\
\hline $\begin{array}{l}\text { "está buscando trabajo y } \\
\text { lamentablemente es siempre } \\
\text { 'bueno, te vamos a llamar'" } \\
\text { (padre de la familia 2) }\end{array}$ & $\begin{array}{l}\text { "que puedan vivir del título } \\
\text { que tienen" (madre de la familia } \\
\text { 20) }\end{array}$ & \\
\hline "reponer en un supermercado" & "que puedan trabajar $y$ & "trabajar afuera" \\
\hline
\end{tabular}




\begin{tabular}{|c|c|c|}
\hline (madre de la familia 1) & $\begin{array}{l}\text { puedan mantenerse" (madre de la } \\
\text { familia 7) }\end{array}$ & (padre de la familia 13) \\
\hline $\begin{array}{c}\text { "terminar en un supermercado } \\
\text { de cajera" (madre de la familia 9) }\end{array}$ & & \\
\hline "manejar un taxi" & "tener su casa" \\
(padre de la familia 2) & (madre de la familia 8) & \\
\hline Fuente: elaboración propia. &
\end{tabular}

Estas expresiones hacen referencia a que los padres categorizan los distintos cursos de vida como más o menos posibles o deseables. El énfasis recae en que sus hijos terminen una carrera terciaria o universitaria, de acuerdo a su preferencia, y que puedan trabajar en un puesto acorde a su formación. Asimismo, proyectan que esa ocupación debería permitirles mantenerse por sus propios ingresos, y "vivir del título". La reproducción de sus hijos e hijas en la clase media conllevaría, además, que puedan tener una propiedad donde vivir.

Como expectativas de ascenso social, aparece, sobre todo, la superación de los niveles educativos de los padres. Así, aunque existe el anhelo de que sus hijos e hijas hagan un posgrado, la posibilidad se descarta porque "es mucha plata" (madre de la familia 8). Por otro lado, algunos padres y madres consideran que las oportunidades que les puede brindar el país en el futuro son deficientes e inciertas e incorporan la posibilidad de que sus hijos e hijas migren al exterior para mejorar sus condiciones de vida.

En cuanto a "riesgos" sociales o destinos que están por fuera de sus horizontes de expectativas de clase media emergen los obstáculos en los estudios, como lo es perder un año de cursada en la facultad por tener materias pendientes de aprobación del año anterior o tomarse "un año sabático". Los padres interpretan estas decisiones de sus hijos e hijas como errores, como si el apoyo material, el aliento y el "calentarle la oreja" durante tantos años para que se sintiesen implicados en las decisiones y trayectorias familiares no hubieran rendido sus frutos. Todo ello conlleva un enorme trabajo emocional, que en general es realizado por las mujeres-madres (Reay y Ball, 1998). Así, viven estas experiencias con "dolor", como una decepción o una "herida narcisista" (madre de la familia 8), que además supone el riesgo de "terminar" en un puesto de cajera o repositor en un supermercado o manejando un taxi. O sea, si bien los títulos universitarios ya no garantizan un puesto laboral de clase media ni un poder adquisitivo como para "vivir del título", el abandono de los estudios universitarios sí se percibe como un riesgo. Emerge lo dificultoso que resulta encontrar un trabajo calificado y se supone que cuanto menor sea el nivel educativo alcanzado, mayor será la necesidad de optar por posiciones subordinadas y, por lo tanto, desjerarquizadas y descalificadas dentro del mercado laboral. Así también, la madre de la familia 8 identifica el riesgo de "ser una bohemia toda la vida", asociado al hecho de que 
algunas carreras universitarias se encuentran más desprestigiadas que otras. Cuenta que su hija decidió no seguir la carrera de Artes del Teatro en una universidad privada, por la consecuente probabilidad de un futuro laboral precario e inestable. En cambio, se inclinó por la carrera de Psicología "que tampoco la terminó porque había otra cosa adentro de ella" (madre de la familia 8).

Para evitar los puestos no deseados, emerge la necesidad de contar con relaciones sociales, "vínculos" con instituciones de prestigio como el Instituto Nacional de Tecnología Agropecuaria (INTA). Como relata el padre de familia 2, le facilita "la cosa" a su hijo para que no tenga que pagar "ese derecho de piso". Más que al derecho de piso en el sentido de favores o tareas extra que tiene que hacer un nuevo empleado, se refiere a puestos no calificados que se asocian a abusos de poder, ingresos bajos y precarización laboral entre otras cosas. En definitiva, trabajos que se encuentran por debajo de sus expectativas de clase.

Así, respecto del mercado laboral, emergen indicadores de una desigualdad que se expresa en múltiples aspectos y no apenas en el acceso o no a un puesto de trabajo. El padre de la familia 17 resalta la posibilidad que él posee como docente de manejar sus horarios de trabajo y sus libertades respecto a la dedicación semanal: "si yo trabajara un turno completo en una fábrica digamos, al revés, soy esclavo de la fábrica. Vos no podés decir 'me voy y chau', te tenés que quedar. (...) Pero mi carga horaria en general fue de dos tercios de la semana, no más" (padre de familia 17). Y relaciona dicha posibilidad de dedicación laboral con el tipo de reconocimiento y comodidad que otorgan ciertas ocupaciones intelectuales: "nunca fue mi objetivo ganar más, sino poder trabajar menos. Trabajar menos quiere decir trabajar cómodamente, o sea, estar en un ambiente en donde a vos te reconocen" (padre de la familia 17). Así también otra madre asocia los estudios superiores con las ocupaciones no manuales y con cierto status que permite una menor carga horaria y una mayor autodeterminación de los tiempos y ritmos de trabajo:

Si yo estudio tengo más opciones, más posibilidades. No tengo por qué terminar siendo operario en una fábrica, si puedo tener otras posibilidades. No porque desmerezca el trabajo de un operario pero no es lo mismo trabajar doce horas para cuando yo cumplo cuatro horas. Por ser un profesional gano exactamente lo mismo. Aparte me da otras posibilidades de elección, 'no, no me gusta acá, bueno, me voy a trabajar a otro lado, yo tengo mi profesión, puedo hacerlo'. En cambio de la otra manera, estás como limitado a lo que te dan y a lo que el trabajo repetitivo y a todo lo que todos los días lo mismo. (Madre de la familia 8).

Al interpretar sus propias trayectorias laborales, otros padres y madres entrevistados también dan cuenta de "riesgos" sociales vividos en su juventud: "yo trabajo desde los 14, 15 años eh. ¿Sí? Trabajaba limpiando terrenos baldíos, trabajé de mozo, trabajé de heladero, eh vendí estampitas casa por casa. Y acá empecé de cadete" (padre de la familia 13). Inferimos que se interpretan como eventos extraordinarios a las formas de 
vida y de trabajo de la clase media por la forma en que relatan estas experiencias laborales, mediante el uso de expresiones como "incluso", "hasta" y "también" que introducen una dificultad y un asombro ante la recapitulación. Por ejemplo: "he hecho trabajos manuales también, eh, ¡las cosas que he hecho!" (Madre de la familia 8). Dichas experiencias resaltan su compromiso con el trabajo y el esfuerzo, aunque también podrían estar motivados por su compromiso social, como en el caso del padre de la familia 2, quien estuvo "dando clase de Literatura y Lengua en el Gran Buenos Aires al lado de la villa en Bernal en el año 83, 84" (padre de familia 2).

En las familias con hijos e hijas menores, los "riesgos" sociales no se relacionan con los puestos laborales y el poder adquisitivo sino con sus salidas, consumo de drogas y alcohol y casos de embarazo adolescente. También aparece el "exceso" vinculado a prácticas deportivas de alto rendimiento. Las decisiones tomadas al respecto tienen que ver con la educación acerca del cuidado de la salud, la asistencia a un club y la formación de un grupo de pertenencia en esa comunidad, la relevancia asignada a las prácticas deportivas y otras actividades recreativas en familia. Por ejemplo:

Todo esto de los robos, de la noche, del alcohol, de las drogas, todo eso es hoy una de las preocupaciones mayores. Digo, a mí no me preocupa si tienen una casa o no, por ahí mi mamá estaba preocupada [por] si yo iba a tener una casa o no. Hoy yo creo que para los hijos es algo diferente, veo un mundo bastante complicado en general. (Madre de la familia 12).

En contraste con la generación de sus padres, que se preocupaba más por sus bienes materiales y su legado material hacia los hijos, para estos padres las instituciones educativas y deportivas aparecen como espacios de inclusión social, como un entorno para el sano desarrollo de sus hijos: "para mí el factor más que la disciplina, más que el idioma, más que todo, es la parte [de] con quién está, con quién pasa ocho horas por día (...) Sí, el tema social, las motivaciones, con quién está, qué cosas puede compartir en el tiempo libre" (madre de la familia 3). Así, eligen aquellas escuelas e instituciones recreativas y de cuidado de la salud que constituyen "enclaves protegidos para la formación de clases" (Sedden, 2001: 134) y ofrecen un ambiente cultural de autoreconocimiento enraizado en los significados y rutinas compartidas.

\section{Los estereotipos tradicionales de género en la generación de los hijos e hijas de clase media del AMBA}

Hasta aquí hemos abordado los horizontes de expectativas que padres y madres de las familias de clase media expresan sobre el futuro de sus hijos e hijas. Hemos visto que éstas se configuran según las posiciones sociales (de clase) de las familias, en un contexto caracterizado por la desigualdad social. Pero estas diferencias sociales percibidas y esperadas según su posición de clase no operan de manera aislada. La 
socialización y educación familiares además presuponen relaciones sociales que se encuentran diferenciadas por género. En este sentido, vemos que la clase social y el género se entrecruzan, habilitando y limitando los horizontes de expectativas para los hijos e hijas, planteando "jurisdicciones específicas para las diferentes versiones de la realidad común" (Berger y Luckmann, 2008: 207).

Estas conceptualizaciones a menudo son reflexiones sobre sus propias experiencias y prioridades vividas y no necesariamente coincidirán con las prácticas y metas de sus hijos. Como lo muestra la madre de la familia 3, por ejemplo, cuando plantea su sorpresa como padres frente a la decisión de su hijo de estudiar Psicología: "no podíamos creer que fue a la escuela técnica, hizo informática y con medalla, con medalla... y diga que quería estudiar todo lo contrario" (madre de familia 3).

Revisando los temas emergentes en los relatos sobre las expectativas y metas para sus hijos varones y sus hijas mujeres vemos que estos son diferentes cuando introducimos la dimensión de género. A continuación presentamos esas valoraciones en el Cuadro 2.

Cuadro 2: Horizontes de expectativas para los hijos e hijas de clase media del AMBA desde una perspectiva de género

\begin{tabular}{|c|c|c|}
\hline $\begin{array}{c}\text { Horizontes de } \\
\text { expectativas para los hijos } \\
\text { varones }\end{array}$ & $\begin{array}{c}\text { Horizontes de } \\
\text { expectativas para hijos } \\
\text { varones y mujeres }\end{array}$ & $\begin{array}{c}\text { Horizontes de expectativas } \\
\text { para las hijas mujeres }\end{array}$ \\
\hline $\begin{array}{l}\text { "nació, parece, como } \\
\text { ingeniero" (madre de la } \\
\text { familia 6) }\end{array}$ & & $\begin{array}{l}\text { "hacer una maestría" } \\
\text { (madre de la familia 8) }\end{array}$ \\
\hline $\begin{array}{c}\text { "fue a la escuela técnica, } \\
\text { hizo informática y con } \\
\text { medalla" (madre de la familia } \\
\text { 3) }\end{array}$ & $\begin{array}{c}\text { "con la computadora } \\
\text { hasta las tres de la mañana" } \\
\text { (madre de la familia 18) }\end{array}$ & $\begin{array}{l}\text { "siempre está destacándose } \\
\text { entre el } 20 \% \text { de arriba" } \\
\text { (padre de la familia 13) }\end{array}$ \\
\hline \multirow[t]{2}{*}{$\begin{array}{l}\text { "él programa y encima es } \\
\text { muy inteligente" } \\
\text { (madre de la familia 6) }\end{array}$} & & $\begin{array}{l}\text { "tendría que ser diseñadora" } \\
\text { (madre de la familia 9) }\end{array}$ \\
\hline & $\begin{array}{c}\text { "no es estudioso" } \\
\text { (padre de la familia 2) }\end{array}$ & $\begin{array}{l}\text { "el canto y la actuación" } \\
\text { (padre de la familia 5) }\end{array}$ \\
\hline $\begin{array}{c}\text { "es intuitivo" } \\
\text { (padre de la familia 2) }\end{array}$ & $\begin{array}{c}\text { "salir" } \\
\text { (padre de la familia 19) }\end{array}$ & $\begin{array}{c}\text { "le encanta la peluquería" } \\
\text { (madre de la familia 9) }\end{array}$ \\
\hline $\begin{array}{l}\text { "es muy especulador" } \\
\text { (padre de la familia 17) }\end{array}$ & $\begin{array}{c}\text { "es vaga" } \\
\text { (madre de la familia 9) }\end{array}$ & $\begin{array}{c}\text { "quiere ser madre" } \\
\text { (padre de la familia 5) }\end{array}$ \\
\hline "futbolista" & & "ser mamá de dos nenas" \\
\hline
\end{tabular}




\begin{tabular}{|c|c|c|}
\hline (padre de la familia 5) & & (madre de la familia 9) \\
\hline $\begin{array}{c}\text { "bombero" } \\
\text { (padre de la familia 5) }\end{array}$ & $\begin{array}{c}\text { "tener un kiosco" } \\
\text { (madre de la familia 9) }\end{array}$ & $\begin{array}{c}\text { "costurera" } \\
\text { (madre de la familia 9) }\end{array}$ \\
\hline $\begin{array}{c}\text { "manejar un taxi" } \\
\text { (padre de la familia 2) }\end{array}$ & & $\begin{array}{c}\text { "vender ropa, ponerse un } \\
\text { negocio" (madre de la familia 9) }\end{array}$ \\
\hline & \multirow{2}{*}{$\begin{array}{l}\text { "fueron muy metidos en } \\
\text { el deporte, que eso es bueno } \\
\text { para los varones. Para las } \\
\text { nenas también" (madre de la } \\
\text { familia 15) }\end{array}$} & $\begin{array}{l}\text { "Maestra si quieren" } \\
\text { (madre de la familia 9) }\end{array}$ \\
\hline $\begin{array}{c}\text { "los chicos al club, el } \\
\text { deporte" (madre de la familia } \\
\text { 15) }\end{array}$ & & $\begin{array}{l}\text { "quiere ser maestra jardinera" } \\
\text { (madre de la familia 9) }\end{array}$ \\
\hline & & $\begin{array}{c}\text { "me dijo 'má, yo quiero ser } \\
\text { maestra'" (madre de la familia 8) }\end{array}$ \\
\hline $\begin{array}{l}\text { "mantener la nena y dos } \\
\text { chicos" (madre de la familia } \\
\text { 15) }\end{array}$ & & $\begin{array}{l}\text { "cajera en el supermercado" } \\
\text { (madre de la familia 16) }\end{array}$ \\
\hline \multirow[t]{2}{*}{$\begin{array}{c}\text { "rebelde" } \\
\text { (madre de la familia 14) }\end{array}$} & & $\begin{array}{l}\text { "todo lo que es basura y } \\
\text { reciclado" } \\
\text { (madre de la familia 14) }\end{array}$ \\
\hline & & $\begin{array}{c}\text { "cuidar los hijos, cuidar las } \\
\text { parejas" (madre de la familia 15) }\end{array}$ \\
\hline
\end{tabular}

Fuente: elaboración propia.

Nota: En los horizontes de expectativas para los hijos varones y mujeres reproducimos algunos ejemplos que aparecieron repetidos en otras familias para otro género.

A partir del análisis de estas expectativas y metas podemos decir, en primer lugar, que varones y mujeres se conceptualizan en espacios físicos diferentes. En cuanto a sus actividades y gustos, los hijos se ven asociados a espacios externos y de actividades en base a lo físico, la competencia y el deporte, mientras que las actividades y gustos de las hijas se asocian a espacios interiores donde poder cuidar del cuerpo, la estética y el medio ambiente a la vez que charlar y estudiar.

En segundo lugar, en cuanto a su futuro ocupacional, la masculinidad de los varones ya no se ve asociada a la competencia y al físico sino que adquiere una forma más "de clase media" basada en el dominio y la demostración de conocimientos específicos y habilidades relacionadas con la informática (Connolly, 2004), la matemática (Cvencek, Meltzoff y Greenwald, 2011) y la ciencia (Nosek, Smyth, Sriram, Lindner, Devos, Ayala y Greenwald, 2009). Los padres entrevistados resaltan que sus hijos varones son menos estudiosos pero más intuitivos, que son inteligentes y saben programar. En cambio, las actividades de las hijas mujeres (en concordancia con las actividades y gustos actuales) 
se asocian con el diseño de indumentaria y la costura, la peluquería y la docencia. La capacidad de enseñar es una cualidad presupuesta desde pequeñas en las hijas mujeres. Como lo describe un padre, "naturalmente" son estudiosas, tienen cierta facilidad para entender y hacer entender a los demás: "y ella misma [mi hija] dice los grupos cuánto les cuesta por ahí entender algo o no. O sea, en casa está siempre lleno de chicos que ella les está enseñando, ¿no? Explicando. Eh ayudándolos para... para llegar" (padre de la familia 13).

En tercer lugar, vemos que las metas de las hijas se asocian con aspectos vinculados a la maternidad: tener hijos, cuidarlos y cuidar de la pareja, mientras que los hijos no se asocian con la paternidad, sino con un rol productivo fuera del hogar y su rol de proveedores económicos respecto de la familia. Por ejemplo, una madre es muy explícita al respecto de los roles de género en la construcción familiar. Cuando le preguntamos acerca de si sus hijos varones estaban en pareja o no, ella mostró su preocupación porque todavía no han formado pareja y nos contó acerca de los consejos que da a sus hijos al respecto. Ella dice:

No encontraron la niña [risas]. Y no pueden. Yo [les] digo 'fuerza varón, porque si no conseguís un trabajo... no tenés un título en la mano y no conseguís trabajo bien, ya cuesta con el título, imaginate sin título, olvídate. Ninguna niña [se] va a querer casar [con vos]'. ¿Cómo va a mantener la nena y dos chicos? [Risas] (Madre de la familia 15).

En estos horizontes de expectativas para sus hijos e hijas se encuentra subyacente un modelo de "familia tipo" de clase media: "sueña para un futuro formar una familia, o sea, quiere ser madre, le encanta todo el tema de chiquitos y qué sé yo. Un poco eso, la misma vida que vio, digamos, para ella" (padre de la familia 5). Se trata de una familia nuclear con dos hijos, un padre proveedor y una madre ama de casa o con un empleo de medio tiempo que le permita "cuidar" del hogar, en concordancia con los estereotipos tradicionales de género y el rol reproductivo que siguen presumiendo para las hijas mujeres:

Yo quiero que estudien, quiero lo que quieran. Ni sabe ella qué va a seguir ni nada pero algo, lo que les guste, lo... Yo tiro para mi profesión [docente]. [Risas] Porque siempre les digo a ellas 'si ustedes quieren tener una familia o algo la verdad que estaba bueno' porque estás con ellas [se refiere a sus hijas] y en las vacaciones estás con ellas, no es que tenis que ir quince días solo. (Madre de la familia 9).

Estos horizontes de sentido pueden no ser conscientes para los padres y madres entrevistados, en tanto pueden remitir a sus experiencias biográficas previas y estar expresando cómo el carácter opaco y limitado del acervo de conocimiento influye 
sobre la proyección y la identidad personal de los padres y madres sobre sus hijos e hijas. De hecho, investigaciones llevadas a cabo tanto desde las perspectivas psicológica como sociológica muestran que las prácticas cotidianas familiares están profundamente diferenciadas por género (Morro, 2006). Y estas familias entrevistadas lo confirman cuando comentan la forma en que organizan el hogar y cómo se dividen las tareas entre sus miembros. Por ejemplo, una madre relata respecto de cuáles eran sus metas durante su juventud: "mi sueño era tener mi familia, como toda niña, encontrarse el amor de su vida y seguir adelante. $Y$ bueno, se me lo dio. Encontré al hombre que realmente quise, con él hice mi vida" (madre de la familia 15). De acuerdo a lo que ella postula como sueño de "toda" niña podríamos decir que los estereotipos tradicionales de género forman parte de las tipificaciones de sentido común de la clase media. Son categorías de la percepción del mundo que han adquirido en su socialización y que funcionan "hasta nuevo aviso" organizando la experiencia de acuerdo con las recetas sociales conocidas.

Siguiendo a Butler (1998) podemos decir que el género no es una esencia que haya que exteriorizar, ni tampoco una identidad estable en el sentido de un yo generalizado permanente. Más bien "es un acto que ya estuvo ensayado, muy parecido a un libreto que sobrevive a los actores particulares que lo han utilizado, pero que requiere actores individuales para ser actualizado y reproducido una vez más como realidad" (p. 306307). El género "es una identidad débilmente constituida en el tiempo" (p. 297) por medio de una repetición estilizada de actos que "es a la vez reactualización y re experimentación de un conjunto de significados ya socialmente establecidos; es la forma mundana y ritualizada de su legitimación" (p. 307).

Así, cuando los padres y madres entrevistados diferencian los horizontes de expectativas para sus hijos e hijas, de alguna forma reproducen y legitiman en el nivel de las familias una estructura de oportunidades que es desigual según género. Lo que se transmite intergeneracionalmente es el (re)conocimiento de dicha tipificación de oportunidades y actividades a ser desempeñadas, independientemente de que las tareas y actividades específicas de referencia vayan cambiando con el tiempo:

En otra época se hacían más los cultos, entonces mandaban a las chicas a estudiar piano y a los varones, no sé... equitación, ponele (...). Hoy por hoy no, es a ver qué eh reloj tenés o qué auto manejás. Cambiaron quizás ese tipo de cuestiones, pero... pero bueno, cada uno igual, creo que es cuestión de cada uno ponerse sus propios referentes o no. (Madre de la familia 14).

Aquí la madre entrevistada resalta que los consumos culturales también están diferenciados por género y que "cada uno" tiene cierta capacidad de agencia para "ponerse" sus propios referentes de género y poner en cuestión cierto acervo incuestionado de conocimientos y actos. Un ejemplo de estos nuevos referentes lo 
proporciona una madre que reflexiona sobre "esta onda que ahora... que se van a vivir solos; a mí me parece buenísimo porque aprenden a todo los varones: a lavar los platos, a limpiarse la casa, me parece genial, genial" (madre de la familia 16). Esta madre describe un nuevo contexto social en el cual los jóvenes retrasan su nupcialidad a la vez que se independizan de la casa de los padres. Ello permitiría "ampliar el campo cultural corporal con performances subversivas" (Butler, 1998: 314) en relación a los estereotipos tradicionales de género en el mantenimiento del hogar.

\section{Conclusiones}

Hemos abordado el complejo campo significativo y motivacional implícito en los horizontes de expectativas que estos padres y madres de clase media tienen para sus hijos e hijas, y analizamos la clase social y el género como constitutivos, en gran medida, de los caminos que persiguen de acuerdo a su percepción de biografías típicas. Los proyectos de reproducción social en la clase media influyen poderosamente en las decisiones, acciones y actitudes de los padres y madres hacia sus hijos e hijas en cuanto a: (i.) la perpetuación de la imagen que tienen de sí como familia, con sus valores y costumbres, sus trayectorias educativas y ocupacionales; (ii.) la intención de protección o sobreprotección respecto de "riesgos" sociales o destinos que están por fuera de sus horizontes de expectativas de clase media; (iii.) una clara definición de metas y jerarquización de ellas según ámbitos de existencia y prioridades de consecución.

A pesar de la variedad en la composición de los hogares y las edades de los hijos e hijas, las familias comparten cierta incertidumbre respecto de sus cursos de vida y destinos de clase. Aun así, encontramos diferencias en cuanto a cómo la conceptualizan. Algunas familias ponderan una incertidumbre de tipo positiva, en el sentido de posibilidades abiertas, mucha libertad y una singularización creciente de los cursos de vida. Otras familias interpretan que el futuro está marcado por cierta incertidumbre negativa, en el sentido de imprevisibilidad e inseguridad respecto de su posición social de destino. En este sentido, nos preguntamos por las razones de estas visiones negativas y positivas en diferentes familias. Por un lado, entran en relación con su ubicación dentro de diferentes estratos de la clase media $y$, por otro, con sus trayectorias familiares, con sus conflictos y constricciones vividas en generaciones previas. En base a este acervo de conocimiento incorporado, las familias de clase media entrevistadas van tomando decisiones previendo y anticipando los riesgos percibidos en cuanto a la salud y educación de sus hijos e hijas. Sus decisiones suponen más herramientas para enfrentar los desafíos a los que la incertidumbre futura pudiera exponerlos.

En cuanto al género, que lo incorporamos como una dimensión de análisis emergente, sugerimos que desde muy temprana edad, y aun antes de que surjan diferencias en el rendimiento académico y aspiraciones futuras de sus hijos e hijas, 
circulan en la familia conceptos de sí mismos que asocian a los varones y a las mujeres con los estereotipos tradicionales de género. Se asocia a los varones con capacidades técnicas en cuanto a ocupaciones y con capacidades físicas en cuanto a sus actividades de ocio, es decir, espacios productivos o no, pero exteriores. Las mujeres, en cambio, se asocian con el cuidado de otros, la docencia y la estética, todas actividades de servicio ya sea dentro o fuera del hogar. Estos padres y madres imaginan que sus hijas se insertarán laboralmente en ocupaciones "típicamente femeninas", es decir, aquellas que son definidas por el carácter de sus tareas como una extensión de la labor doméstica (Jelin, 2010).

Como es evidente en los relatos de estos padres y madres, las clases sociales y los estereotipos de género son categorías de percepción del mundo que han adquirido en su socialización y sus experiencias. Son elementos dinámicos, negociados dentro de procesos de interacción social, pero que en tanto se constituyen al interior de un grupo de personas que comparten una posición social, también pueden ser leídos, en términos de Schütz, como sentidos que permanecen estables - de alguna forma, invariables- en la vida de las personas.

\section{Referencias bibliográficas}

Ball, S. J. (2003). Class Strategies and the Education Market: The middle classes and social advantage. London: RoutledgeFalmer.

Berger, P. y Luckmann, T. (2008). La construcción social de la realidad. Buenos Aires: Amorrortu.

Bourdieu, P. (1998). La distinción. Criterios y bases sociales del gusto. Madrid: Taurus.

Connolly, P. (2004). Boys and Schooling in the Early Years. London: Routledge Falmer.

Dalle, P. (2009). La movilidad social intergeneracional desde la clase trabajadora en el AMBA (2004-2005). Un análisis a nivel macro y micro social de los canales de ascenso, reproducción y descenso en la estructura de clases (Tesis de maestría no publicada). Facultad de Ciencias Sociales, Universidad de Buenos Aires, Buenos Aires.

Dreher, J. (2012). Zur lebensweltlichen Konstitution sozialer Ungleichheiten und symbolischer Machthierarchien. En Angewandte Phänomenologie: Zum Spannungsverhältnis von Konstruktion und Konstitution (pp. 125-145). Wiesbaden: Springer VS.

Germani, G. (1963). Movilidad social en la Argentina. En S. M. Lipset y R. Bendix, Movilidad social en la sociedad industrial (pp. 317-367). Buenos Aires: Eudeba.

Jelin, E. (2010). Pan y afectos: la transformación de las familias. 2da edición. Buenos Aires: Fondo de Cultura Económica.

Krause, M. (2014). Un análisis del sentido que familias de clase media metropolitana le asignan a sus prácticas cotidianas en educación y salud (Tesis de maestría no 
publicada). Facultad de Ciencias Sociales, Universidad de Buenos Aires, Buenos Aires.

Patton, M. Q. (2002). Qualitative Research \& Evaluation Methods (3 ed.). Thousand Oaks: Sage.

Schütz, A. (1993). La comprensión significativa del mundo social: Introducción a la sociología comprensiva. Barcelona: Paidós.

Schütz, A. (2003). El problema de la realidad social: Escritos I. Buenos Aires: Amorrortu.

Schütz, A. y Luckmann, T. (2001). Las estructuras del mundo de la vida. Buenos Aires: Amorrortu.

Wortman, A. (2003). Cultura y subjetividad en Buenos Aires. En Wortman, A. Pensar las clases medias: consumos culturales y estilos urbanos en la Argentina de los noventa (pp. 35-51). Buenos Aires: La Crujía.

\section{Revistas}

Boltanski, L. y Chiapello, E. (2005). The new spirit of capitalism. International Journal of Politics, Culture, and Society, 18 (3), 161-188.

Cvencek, D., Meltzoff, A. N. y Greenwald, A. G. (2011). Math-Gender Stereotypes in Elementary School Children. Child Development. 82 (3), 766-779.

Morrow, V. (2006). Understanding Gender Differences in Context: Implications for Young Children's Everyday Lives. Children \& Society. 20, 92-104.

Nosek, B. A., Smyth, F. L., Sriram, N., Lindner, N. M., Devos, T., Ayala, A. y Greenwald, A. G. (2009). National differences in gender-science stereotypes predict national sex differences in science and math achievement. Proceedings of the National Academy of Sciences, 106 (26), 10593-10597.

Reay, D. y Ball, S. J. (1998). Making their minds up: family dynamics of school choice. British Educational Research Journal, 24 (4), 431-448.

Sedden, T. (2001). Revisiting inequality and education; a reminder of class; a retrieval of politics; a rethinking of governance. Melbourne Studies in Education, 42 (2), 131144.

\section{Referencias electrónicas}

Butler, J. (1998). Actos performativos y constitución del género: un ensayo sobre fenomenología y teoría feminista. Debate Feminista. 18 (9), 296-314. Recuperado de: http://www.debatefeminista.com/PDF/Articulos/actosp433.pdf

Jorrat, J. R. (2005). Aspectos descriptivos de la movilidad intergeneracional de clase en Argentina: 2003-2004. Laboratorio: Estudios sobre Cambio Estructural y Desigualdad Social, 7 (17-18), 5-10. Recuperado de: http://www.lavboratorio.sociales.uba.ar/textos/lavbo 17-18.pdf

Knoblauch, H. (1999). Metaphors, Transcendence and Indirect Communication: Alfred Schütz' Phenomenology of the Life-World and the Metaphors of Religion. En L. 
Boeve y K. Feyaerts (Eds.), Metaphor and God-Talk (pp. 75-94). Bern: Peter Lang. Recuperado http://www.ssoar.info/ssoar/bitstream/handle/document/753/ssoar-1999knoblauch-metaphors.pdf? sequence $=1$

Krause, M. (noviembre, 2011). Un acercamiento a las estructuras de desigualdad objetivas en la obra de Schütz. VI Jornadas de Jóvenes Investigadores. Instituto de Investigaciones Gino Germani, Universidad de Buenos Aires, Buenos Aires. Recuperado de: http://webiigg.sociales.uba.ar/iigg/jovenes investigadores/6jornadasjovenes/EJE \%2012\%20PDF/eje12 krause.pdf

Martuccelli, D. (2010). La individuación como macrosociología de la sociedad singularista. Revista Persona y Sociedad, XXIV (3), 9-29. Recuperado de: http://www.uff.br/observatoriojovem/sites/default/files/documentos/Martuccelli La individuacion como macrosociologia de la sociedad singularista.pdf

Melián, M. C. Fernández; de la Fuente, J. Rodríguez y Clemenceau, L. (2013). Tendencias de movilidad social en la Ciudad Autónoma de Buenos Aires 2012-2013: entre ascensos, descensos y reproducción. VII Jornadas de Jóvenes Investigadores. Instituto de Investigaciones Gino Germani, Universidad de Buenos Aires, Buenos Aires. http://jornadasjovenesiigg.sociales.uba.ar/files/2013/10/eje12 Clemenceau.pdf 